\section{As investigações dos fenômenos psíquicos/ espirituais no século XIX: sonambulismo e espiritualismo, 1811-1860}

\author{
Investigations of psychic/ \\ spiritual phenomena in \\ the nineteenth century: \\ somnambulism and \\ spiritualism, 1811-1860
}

\section{Marcelo Gulão Pimentel}

Historiador; mestrando em Saúde Brasileira/Faculdade de Medicina da Universidade Federal de Juiz de Fora (UFJF); membro do Núcleo de Pesquisas em Saúde e Espiritualidade (Nupes)/UFJF. Av. Eugênio do Nascimento, $s / n$ 36038-330 - Juiz de Fora - MG - Brasil mgulao@yahoo.com.br

\section{Klaus Chaves Alberto}

Professor, UFJF; coordenador, área de humanas/Nupes. Campus Universidade Federal de Juiz de Fora - Faculdade de Engenharia - Curso de Arquitetura e Urbanismo - Martelos 36000-000 - Juiz de Fora - MG - Brasil

klaus.alberto@uff.edu.br

\section{Alexander Moreira-Almeida}

Professor, Faculdade de Medicina/UFJF; diretor, Nupes. Av. Eugênio do Nascimento, $s / n$ 36038-330 - Juiz de Fora - MG - Brasil alex.ma@uff.edu.br

Recebido para publicação em fevereiro de 2014. Aprovado para publicação em outubro de 2014.

http://dx.doi.org/10.1590/S0104-59702016005000010
PIMENTEL, Marcelo Gulão; ALBERTO, Klaus Chaves; MOREIRA-ALMEIDA, Alexander. As investigações dos fenômenos psíquicos/espirituais no século XIX: sonambulismo e espiritualismo, 1811-1860. História, Ciências, Saúde-Manguinhos, Rio de Janeiro, v.23, n.4, out.-dez. 2016, p.11131131.

\section{Resumo}

No início do século XIX, investigações sobre a natureza de fenômenos psíquicos/espirituais como transes e supostas aquisições de informações indisponíveis aos canais sensoriais normais geraram grande debate no meio científico. Este artigo discute as principais explicações oferecidas pelos pesquisadores dos fenômenos psíquicos entre 1811 e 1860 , concentrando-se nos dois movimentos principais no período: sonambulismo magnético e espiritualismo moderno. As investigações desses fenômenos geraram diversas teorias, sem que se chegasse a consenso, mas trouxeram implicações para a compreensão da mente e de seus transtornos, notadamente na área do inconsciente e da dissociação, constituindo-se como parte importante da história da psicologia e da psiquiatria.

Palavras-chave: sonambulismo; transe; mesmerismo; mediunidade espiritual.

\section{Abstract}

In the early nineteenth century, investigations into the nature of psychic/ spiritual phenomena, like trances and the supposed acquisition of information unattainable using normal sensory channels, prompted much debate in the scientific arena. This article discusses the main explanations offered by the researchers of psychic phenomena reported between 1811 and 1860, concentrating on the two main movements in the period: magnetic somnambulism and modern spiritualism. While the investigations of these phenomena gave rise to multiple theories, they did not yield any consensus. However, they did have implications for the understanding of the mind and its disorders, especially in the areas of the unconscious and dissociation, constituting an important part of the history of psychology and psychiatry.

Keywords: somnambulism; trance; mesmerism; spiritual mediumship. 
A palavra "psíquico" é frequentemente empregada para referir-se a um conjunto de fenômenos também nomeados como mesméricos, ${ }^{1}$ mediúnicos, ${ }^{2}$ espirituais, ${ }^{3}$ metapsíquicos $^{4}$ e parapsíquicos ${ }^{5}$ (Society..., 1882, p.2). Ela designa também uma série de manifestações em que "a mente (espírito ou alma, dependendo da abordagem de cada autor) poderia transcender ao corpo físico e assim mostrar sua independência do corpo" (Alvarado, 2013, p.157). Essas manifestações abrangem relatos de comunicação direta entre mente e mente, aquisições de informações indisponíveis aos canais sensoriais normais, previsões de acontecimentos futuros, batidas e movimentos inteligentes de objetos sem a aplicação aparente de força sobre eles, entre outros fenômenos.

Desde o surgimento do sonambulismo magnético, na primeira metade do século XIX, é possível encontrar análises de intelectuais sobre a natureza desses fenômenos, envolvendo grande número de cientistas e investigadores de alto nível, como: Michael Faraday, físico e químico considerado um dos cientistas mais influentes da história (James, 2010); o médico e naturalista William Carpenter, um dos primeiros estudiosos a cogitar a existência de mecanismos inconscientes na mente humana (Crabtree, 1993, p.254-256; Oppenheim, 1985, p.247-249); o físico e primeiro-ministro francês François Arago; e o médico cirurgião James Braid, iniciador da hipnose científica (Gauld, 1968). Um dos principais objetivos deles era entender as causas desses fenômenos e suas implicações para a compreensão da mente, de seus transtornos e da própria natureza humana (Ellenberger, 1970).

O sonambulismo magnético e o espiritualismo moderno foram duas propostas de investigação dos fenômenos psíquicos que não se consolidaram no meio científico. Todavia, elas foram tema de diversos estudos, nos quais se notam concepções distintas. A primeira considera o sonambulismo magnético e o espiritualismo moderno movimentos místicos e supersticiosos que não resistiriam a uma análise metodológica mais rigorosa. Uma segunda concepção reconhecia a importância do estudo desses fenômenos para o desenvolvimento de uma nova abordagem da mente humana, a partir de seus mecanismos involuntários ou inconscientes. A terceira concepção teria sido resultado de um intenso debate entre a Escola de Nancy, liderada pelo fisiologista Hippolyte Bernheim, e a Escola de Salpêtrière, organizada e dirigida pelo neurologista Jean Martin Charcot. Bernheim entendia que o fenômeno seria efeito da "sugestão" dos indivíduos avaliados, logo, não podendo ser classificado como patológico (Ellenberger, 1970).

Já Charcot classificava os fenômenos como uma patologia fruto de ilusão ou delírio de seus adeptos. Essa visão contribuiu para que grande parte dos comportamentos e atitudes das manifestações psíquicas fossem classificadas como transtornos mentais pela nosografia francesa a partir da segunda metade do século XIX (Gonçalves, Ortega, abr.-jun. 2013; Le Maléfan, Evrard, Alvarado, 2013). No Brasil, em particular, essas pesquisas repercutiram por meio dos adeptos do pensamento do educador e pesquisador francês Allan Kardec, fundador do espiritismo. Ainda hoje, grupos espíritas desenvolvem terapias baseadas na ideia de que entidades invisíveis (espíritos ou almas) podem intervir nas funções mentais de alguns indivíduos como: a vontade, a inteligência, a consciência, os sentimentos e a razão (Jabert, jan.-mar. 2011; Almeida, 2007; Giumbelli, 1997).

Apesar de sua relevância histórica, essas pesquisas constituem uma área de interesse ainda periférica para as ciências da mente, e as obras sobre esse tema são praticamente desconhecidas 
por autores atuais em ciências comportamentais e por historiadores de psicologia e psiquiatria (Valentine, 2012).

Nesse sentido, pretende-se apresentar uma breve revisão de alguns dos principais pesquisadores que se dedicaram aos estudos dos fenômenos psíquicos em países como França, Inglaterra, Alemanha e EUA. Busca-se, aqui, expor um panorama dos debates acerca das explicações dos fenômenos psíquicos.

A análise será concentrada entre 1811, ano da publicação da primeira obra dedicada a pesquisas, experiências e observações sobre o sono magnético, e a década de 1850, quando diferentes explicações para as manifestações psíquicas ligadas ao espiritualismo moderno e ao fenômeno das mesas girantes tiveram grande repercussão nos EUA e em vários países europeus.

Daremos ênfase às análises vinculadas ao sonambulismo e ao espiritualismo, relacionando essas pesquisas com o desenvolvimento de ideias que contribuíram para o maior entendimento da mente humana.

\section{O sonambulismo magnético e os fenômenos psíquicos}

Mesmer chegou a Paris em 1778, introduzindo novas técnicas e ideias adaptadas ao espírito iluminista que vigorava na época (Ellenberger, 1970). Médico formado na Universidade de Viena, anunciou sua descoberta sobre um fluido difuso no universo que penetrava e cercava todos os corpos. A doença seria gerada pelo obstáculo à circulação do fluido pelo corpo tal substância teria propriedades semelhantes a um ímã (Mesmer, 1779). Assim, Mesmer desenvolveu uma terapia, conhecida como mesmerismo ou magnetismo animal, na qual o fluido seria controlado e fortalecido a partir de sessões de "mesmerização". O magnetizador transmitiria o fluido por meio da imposição das mãos ou por meio de massagens nos polos do corpo para a superação do obstáculo (Mesmer, 1779, p.8-30). Junto com as curas realizadas, o magnetismo animal também chamava a atenção por uma série de fenômenos que surgiam como "efeitos colaterais" da mesmerização.

Armand Marie Jacques de Chastenet, o marquês de Puységur (1751-1825), interpretou o magnetismo animal sob um novo aspecto. Ele observou que alguns magnetizados pareciam despertos enquanto dormiam, o que foi chamado de sonambulismo magnético ou sono artificial (Puységur, 1811).

Para Puységur (1809, p.99-114), fazia parte do tratamento o sono magnético, pois nesse alguns pacientes atingiam uma espécie de lucidez sob a qual adquiriam habilidades clarividentes, como a de obter informações sem a utilização dos canais sensoriais conhecidos, diagnosticar sua própria doença, prever o seu curso e prescrever os medicamentos necessários para a cura. Esse fenômeno, conhecido como clarividência médica, foi descrito por Puységur em seus livros, que ressaltam casos de cura alcançados e a validade da terapia sonambúlica, embora reconhecendo que as habilidades clarividentes manifestadas durante o sono magnético tinham origem em forças psicológicas desconhecidas (Puységur, 1811).

Outros relatos sobre o fenômeno psíquico também podem ser encontrados nos discursos de magnetizadores do período. Eles informavam que durante as sessões de magnetismo o paciente adquiria o aumento de algumas habilidades cognitivas, intelectuais e sensoriais (Monroe, 2008, p.68). Declarações sobre os magnetizados apontavam casos de curas espirituais, 
leitura de mensagens armazenadas em recipientes fechados e captação do pensamento de outras pessoas (Crabtree, 1993, p.40-45).

Em busca de uma conclusão definitiva sobre as causas dos fenômenos psíquicos, diversos pesquisadores se debruçaram sobre o tema, especialmente os magnetizadores que se autoproclamavam peritos no estudo experimental da mente humana (Monroe, 2008, p.64).

\section{As abordagens dos fenômenos psíquicos ligados ao sonambulismo magnético}

Na tradição mesmérica, os magnetizadores possuíam, ao menos, quatro diferentes hipóteses para explicar os fenômenos psíquicos: a fluidista, a psicofluidista, a espiritualista e a animista (Méheust, 1999).

A hipótese fluidista era defendida por mesmeristas ortodoxos que não absorveram as modificações da teoria do magnetismo animal proposta pelos discípulos de Mesmer. Apoiados nos métodos e resultados terapêuticos do mesmerismo, eles consideravam que as alterações físicas e psicológicas que caracterizavam o fenômeno psíquico eram resultado da ação do fluido e seriam nocivas ao sonâmbulo, não devendo ser estimuladas (Méheust, 1999).

Os psicofluidistas sustentavam que as manifestações psíquicas tinham origem em forças psicológicas desconhecidas acionadas por intermédio do fluido magnético (Ellenberger, 1970). Entendiam que o fenômeno poderia demonstrar a ação da mente fora do corpo, devendo ser estudada como uma faculdade humana (Méheust, 1999).

Defensor da hipótese, Joseph Deleuze (1753-1835) foi um dos primeiros pesquisadores a oferecer explicações aos fenômenos psíquicos que emergiram a partir do sono magnético. Discípulo de Puységur, Deleuze sustentava a ideia de que o estado sonambúlico possuiria diferentes gradações e apenas alguns sonâmbulos desenvolveriam uma suscetibilidade especial, como a de captar pensamentos e sensações de outras pessoas no seu entorno. Haveria, assim,

na maioria dos sonâmbulos um desenvolvimento da sensibilidade de que não podemos ter nenhuma concepção. Eles são suscetíveis de receber a influência de tudo o que os rodeia e, principalmente, a partir de seres vivos. Eles não só são afetados por emanações físicas, ou os eflúvios de corpos vivos, mas também, em um grau muito mais surpreendente, pelos pensamentos e sentimentos dos que os rodeiam, ou que estão ocupados com eles (Deleuze, Foissac, 1850, p.55-56).

O fenômeno psíquico seria resultado da captação, pela mente do sonâmbulo, de fluidos magnéticos emanados por seres humanos e também por objetos. Deleuze afirmava que, nos fluidos, estariam registradas informações que permitiriam entender outras manifestações psíquicas, como descrever um evento que não testemunhou e reconhecer a origem e a propriedade de um objeto (Deleuze, Foissac, 1850, p.38-62).

A ação do fluido também explicaria os fenômenos psíquicos da clarividência e da clarividência médica. Para os psicofluidistas, a manifestação não seria considerada sobrenatural. Eles explicavam que a inteligência de alguns sonâmbulos seria suscetível ao fluido, que expandiria sua capacidade de estabelecer relações causais, gerando as previsões (Strombeck, 1814; Teste, 1840, p.238).

A tese dos psicofluidistas era considerada insuficiente pelos magnetizadores espiritualistas. Esse grupo defendia que as manifestações psíquicas observadas só poderiam ser explicadas 
pela atuação de seres inteligentes invisíveis (Crabtree, 1993). Segundo essa hipótese, o sono magnético dissociaria temporariamente a alma do corpo e, em alguns casos, ela entraria em contato com o mundo espiritual (Cahagnet, 1850, p.10; Delaage, 1851; Jung-Stilling, 1854, p.48-49). Essa proposição teria sido deduzida por meio do depoimento de sonâmbulos.

O médico alemão Justinus Kerner, nos quatro anos em que tratou de Frederica Hauffe, conhecida como "a vidente de Prevorst", constatou que as previsões dela ocorridas durante o estado sonambúlico poderiam ser classificadas como "dupla vista". A vidente, para ele, entraria em contato com espíritos que lhe transmitiriam as informações sob a forma de símbolos. Em um dos casos, Kerner $(1855$, p.33) ilustrou a "dupla vista" citando o seguinte depoimento de Hauffe: "Eu vejo N na lua, no entanto, ele ainda vive sobre a terra, mas eu o vejo ali como se fosse por antecipação. Em um quarto de um ano, ele vai morrer, e meu pai vai ser o primeiro a saber de sua morte". Kerner complementou o depoimento afirmando que a pessoa citada teria morrido no período dito por Hauffe e a notícia da morte foi dada pelo pai dela.

O fenômeno psíquico da "dupla vista" observado por Kerner (1855, p.32) o levou a concluir que "a alma humana, mesmo nesta vida, está em constante comunicação com o mundo espiritual, e que estes são suscetíveis de impressões mútuas, mas, desde que tudo corra bem, essas impressões passam despercebidas".

Os espíritos agiriam diretamente sobre a saúde do homem. Para os magnetizadores espiritualistas, a ação de espíritos demoníacos sobre o indivíduo causaria parte das doenças mentais. Elas poderiam ser curadas por meio de sessões de magnetismo, nas quais a má influência espiritual se manifestaria e seria afastada pelo magnetizador, com o auxílio de espíritos bons ou anjos (Kerner, 1855; Billot, 1839; Cahagnet, 1850).

As ideias dos magnetizadores espiritualistas tiveram pequena adesão na tradição mesmerista. De acordo com o médico Guillaume Pascal Billot, a relutância dos magnetizadores em aceitar essa hipótese se devia ao fato de que uma atuação puramente espiritual não poderia ser estudada pela ciência. Para ele, essa visão seria equivocada, pois restringia a possibilidade de explicação do fenômeno. Billot (1839, p.IX-X) considerava que o "invisível" não significava "não natural", e que a aceitação da hipótese da ação de forças inteligentes invisíveis traria uma revolução nas ciências naturais e novas direções para o seu estudo.

Os magnetizadores animistas, de outro modo, afirmavam que os fenômenos psíquicos possuíam causas exclusivamente psicológicas, sendo interpretados como efeito da imaginação (Cuvillers, 1821). Os argumentos dos espiritualistas sofreram críticas dos magnetizadores animistas; sendo considerados resultado do excesso de credulidade e da falta de cuidado na observação (Bertrand, 1826). Durante a sessão, o magnetizador poderia superexcitar algumas faculdades intelectuais, como a inteligência e a imaginação, enquanto outras faculdades eram anestesiadas por efeito do sonambulismo, como a vontade e a moral (Méheust, 1999, p.15-16).

O médico e magnetizador Alexandre Bertrand (1826) foi um dos principais defensores dessa teoria. Para ele, o sonambulismo artificial atuaria, especialmente, sobre a imaginação do indivíduo. O sonâmbulo seria um autômato sugestionado por seu magnetizador. Os animistas associavam o sonambulismo e os relatos de visão de espíritos de mortos à ação da imaginação patológica, que atuaria como uma "vontade inimiga" do sonâmbulo (Chardel, 1826, p.263-274). 
O debate entre os magnetizadores sobre sonambulismo e a causa dos fenômenos psíquicos teve repercussão fora da tradição mesmérica, o que contribuiu para a formação de um discurso cético em relação à existência dos fenômenos psíquicos.

\section{O discurso cético acerca dos fenômenos psíquicos}

Em geral, o discurso cético entendia os fenômenos psíquicos como efeito da ilusão, da fraude e da credulidade. O francês Julien-Joseph Virey, membro da Academia Real de Medicina de Paris, foi um dos principais críticos do magnetismo animal e da validade dos fenômenos psíquicos gerados por sono magnético. Em artigo publicado no Dictionnaire des sciences médicales (Dicionário das Ciências Médicas), o autor considerava a terapia mesmerista uma prática supersticiosa ineficaz. Concordava parcialmente com a teoria sonambúlica ao afirmar que ela causaria uma espécie de hipersensibilidade cerebral, por causa da qual o sonâmbulo teria seus sentidos estimulados, permitindo-lhe captar as impressões de uma pessoa deixadas em um objeto, a partir do aumento da visão, do olfato e dos outros sentidos (Virey, 1818, p.554-555).

As supostas comunicações com espíritos e a possessão poderiam ser explicadas pela existência de um instinto interno adormecido, sentido como um ser externo pelo indivíduo a ponto de ser confundido com outra entidade (Virey, 1818, p.474-476). Essa concentração interna inconsciente despertada no sonambulismo também explicaria o aumento intelectual do indivíduo magnetizado em relação ao seu estado ordinário de consciência. Ele seria provocado por uma "tensão cerebral" capaz de reunir fragmentos de informação armazenados pelo inconsciente humano (p.478).

Os argumentos de Virey, desqualificando o magnetismo animal, foram contestados publicamente por Deleuze e León Louis Rostan, médico de Salpêtrière e membro da Academia Real de Medicina (Deleuze, 1819; Deleuze, Rostan, 1836).

Em 1825, Rostan foi o responsável pelo verbete "Magnetismo" no Dictionnaire de médecine et de chirurgie pratique (Dicionário de medicina e de cirurgia prática). Nele, sustentou que o magnetismo geraria alterações no sistema nervoso do indivíduo que poderiam ocasionar curas; contudo, tinha dúvidas quanto à validade das manifestações psíquicas, devido à suscetibilidade do magnetizado em relação ao magnetizador (Rostan, 1825).

Por causa da controvérsia entre céticos e magnetizadores, o médico Pierre Foissac (1825) pediu à Academia Real de Medicina o reexame do magnetismo animal, alegando que os meios empregados pela terapia e os seus efeitos haviam mudado desde a condenação de sua prática pela comissão de 1784. A comissão médica investigativa foi instaurada em 1826. O comitê de médicos estudou principalmente os casos ocorridos no Hotel Dieu liderados pelo médicochefe do hospital, Henri-Marie Husson, e pelo magnetizador Jules DuPotet de Sennevoy. O relatório da comissão foi favorável à prática do magnetismo animal e à eficácia da sua terapia (Burdin, Dubois, 1841, p.413-414). O relatório também descrevia experiências com indivíduos em estado sonambúlico que identificavam o número e a cor de cartas de baralho sem usar os olhos; liam trechos de livros com os olhos cobertos e faziam previsões (p.386-389).

A conclusão da comissão trouxe legitimidade ao magnetismo animal e às suas práticas. No entanto, alguns membros da academia continuaram a questionar os efeitos do magnetismo 
animal. Em 1833, o médico Frédéric Dubois (1833, p.6) publicou um panfleto acusando o mesmerismo de ser irracional e ligado ao absurdo e ao miraculoso.

Os questionamentos continuaram no ano seguinte, quando o Dicionário de medicina e de cirurgia prática de 1834 definiu o sono magnético como um problema funcional do sistema nervoso caracterizado, essencialmente, pela diminuição ou supressão total da consciência e de outras faculdades que nos colocam em relação com o mundo exterior (Méheust, 1999, p.16). Em 1837, acusações de fraude relacionadas ao magnetismo animal entre membros da academia geraram um longo debate entre defensores e críticos da terapia, levando à instalação de nova comissão pela Academia de Medicina.

Os autores do verbete, Jean Bouillaud e Frédéric Dubois, foram dois dos nove integrantes da comissão. Dessa vez, as observações não trouxeram resultados conclusivos. Segundo o relatório, os dois sonâmbulos observados falharam na execução dos fenômenos psíquicos. A comissão concluiu pela inexistência dos efeitos do magnetismo animal e das manifestações psíquicas (Burdin, Dubois, 1841, p.506-511).

Husson criticou o relatório, afirmando que cinco dos nove membros da comissão eram previamente contrários à validade do magnetismo animal e dos fenômenos psíquicos. Ainda tinha ressalvas quanto ao método adotado para a realização da experiência. Ele alegou que as observações foram feitas com dois sonâmbulos, mas o ideal seria uma experiência com oito a 15 indivíduos. Como magnetizador, Husson também ressaltou que as condições de indução do sonâmbulo aos fenômenos psíquicos eram impróprias (Burdin, Dubois, 1841, p.517-522). Apesar das críticas, as conclusões do relatório foram mantidas.

Charles Burdin e Pierre Dubois consideram que o parecer favorável ao magnetismo em 1826 foi obtido em um momento em que a academia possuía um grande número de defensores dessa teoria em seu quadro de membros. Para eles, apesar de a academia considerar, desde 1826, a prática mesmerista pouco científica, ela acabou por ceder para não se indispor com os magnetizadores (Burdin, Dubois, 1841). Em 1837, a presença da maioria declaradamente cética na comissão investigativa do magnetismo e dos fenômenos psíquicos indica uma mudança na configuração política da academia, que foi decisiva para a exclusão do magnetismo animal como terapia medicinal.

\section{As investigações do espiritualismo moderno e das mesas girantes}

Em 1848, os fenômenos psíquicos ganham novo fôlego com o surgimento do espiritualismo moderno nos EUA. O movimento foi iniciado por duas jovens irmãs, Catherine e Margaretta Fox, de 12 e 15 anos respectivamente, que viviam em Hydesville, região rural do estado de Nova York (Weisberg, 2004, p.1-8). Essas irmãs foram protagonistas de fenômenos como o movimento, sem causa física aparente, de mesas e outros objetos pesados, além de barulhos similares a batidas nos móveis e nas paredes. No mesmo ano, Catherine, conhecida como Kate, ganhou notoriedade na comunidade por ter desenvolvido um código para interagir com as batidas, afirmando que elas tinham causa inteligente (p.1-8).

Em pouco tempo, as letras do alfabeto passaram a ser soletradas sequencialmente em voz alta, havendo interrupção pela batida quando se alcançava a letra desejada pelo ser inteligente (Doyle, 2007). Desse modo, a família Fox, juntamente com seus vizinhos, teria 
chegado à conclusão de que as batidas foram geradas por Charles B. Rosma, caixeiro viajante assassinado naquela casa e cujo corpo estava sepultado no porão, onde a família Fox mais tarde encontrou a sua ossada (Doyle, 2007).

Narrativas sobre manifestações espirituais são amplamente conhecidas em diversas sociedades ao longo da história, como nas sociedades clássicas greco-romanas, nas raízes judaico-cristãs da sociedade ocidental, passando por oráculos, profetas e xamãs (Hastings, 1991). No entanto, as irmãs Fox foram as primeiras a estabelecer um código de comunicação com os espíritos, sendo chamadas de "médiuns" (Aubrée, Laplantine, 1990, p.15-16). O fenômeno ganhou os jornais americanos e foi batizado por um jornalista como espiritualismo moderno (Weisberg, 2004, p.3).

Até a metade de 1850, cerca de dez mil adeptos transformaram o fenômeno de Hydesville em um movimento social que em pouco tempo se alastraria pela Europa, com os primeiros grupos de espiritualistas modernos desembarcando na Inglaterra em 1853 (Aubrée, Laplantine, 1990, p.16). Em julho de 1852, o jornal católico francês L'Univers já publicava as primeiras notícias sobre o espiritualismo moderno - definiu o movimento como "um magnetismo sem sonambulismo e evocação das almas dos mortos" (Barrier, 1852).

Os espiritualistas disseminaram na Europa sessões de table turning (mesas girantes), que consistiam na reunião de um grupo de pessoas em torno de uma mesa e a formação de uma "corrente", onde geralmente se apoiava a ponta dos dedos sobre a mesa. Após alguns instantes, a mesa iniciaria movimentos circulares sem o uso aparente de força física (Doyle, 2007). Em maio de 1853, o fenômeno já tinha se propagado para diversos países europeus (Aubrée, Laplantine, 1990, p.19-20). Desde os salões literários até as pequenas salas de jantar, pessoas de todas as classes sociais cederam ao espiritualismo moderno e à possibilidade de contatar os mortos.

No mesmo ano, os participantes das sessões mediúnicas instituíram códigos de comunicação pelos quais as mesas passaram a responder a perguntas mediante batidas com seus pés sobre o solo (Cuchet, 2012, p.64-68). Logo, foram estabelecidas formas de contato mais complexas, como o uso de um lápis trespassado em uma cesta ou uma prancheta com um lápis sobre a ardósia. Os participantes colocavam as mãos sobre os aparatos, que por sua vez se movimentavam, formando frases atribuídas aos espíritos. Em sua última etapa, os médiuns desenvolveram formas diversas de comunicação com os supostos espíritos, sendo uma das mais populares a escrita automática, ou mediúnica, pela qual o espírito se comunicaria por meio do médium, utilizando lápis e papel. Eles alegavam que o espírito tomaria posse do seu braço, escrevendo as mensagens, ou que as entidades invisíveis diziam o conteúdo das mensagens como se falassem ao ouvido (Cuchet, 2012, p.64-75).

Em pouco tempo, o tema foi tratado em artigos de jornais e revistas, bem como de tratados científicos que tentaram explicar o movimento das mesas e as comunicações por intermédio dos médiuns (Sharp, 2006, p.49-51). Diversos relatórios tentaram explicar suas causas. Entre elas estavam: fraude ou charlatanismo, ilusão ou alucinação, algum tipo de agente ou força física, o demônio e espíritos desencarnados. 


\section{Charlatanismo}

A suposta demonstração da existência da vida após a morte, pela comunicação mediúnica com espíritos, tornou-se popular nos EUA e na Europa. Muitos médiuns acabaram fazendo disso uma fonte de renda. Junto com as apresentações pagas, surgiram as acusações de charlatanismo. As irmãs Fox, que realizavam excursões a outras cidades apresentando suas habilidades em troca de dinheiro (Weisberg, 2004), tornaram-se foco de investigação dos defensores dessa teoria.

Charles G. Page (1853) publicou um livro dedicado à exposição pública das fraudes cometidas por médiuns, especialmente pelas irmãs Fox. Para ele, as batidas atribuídas aos espíritos eram produzidas pelas irmãs por meio de truques. Porém, reconheceu que sua teoria não explicava como as batidas respondiam corretamente a perguntas particulares sobre pessoas mortas desconhecidas das médiuns, como: nome, doença que as levaram ao óbito e a cidade em que viviam (p.45-73).

Page (1853, p.97) concluiu que os fenômenos psíquicos não passavam de truques, nos quais eram utilizados variados subterfúgios. E mesmo que as manifestações escapassem ao alcance de sua teoria, parecendo autênticas, elas ainda assim seriam truques. Esses truques também poderiam se manifestar de forma mais sofisticada. Segundo a descrição de médicos da universidade de Búfalo, no Buffalo Medical Journal, os estalos teriam origem em movimentos voluntários pouco perceptíveis produzidos por Margaretta Fox, em que sua tíbia se deslocaria lateralmente sobre a superfície inferior do fêmur, gerando o estalo (Flint, Lee, Coventry, 1851, p.629-33).

Em sua experiência, os médicos examinaram as principais acusações de fraude feitas contra as irmãs Fox. Eles pediram que mulheres examinassem "cuidadosa" e "repetidamente" as irmãs, buscando excluir a possibilidade de produzirem as batidas de forma artificial, utilizando o vestido para gerar os sons, amarrando-os em portas ou escondendo objetos sonoros dentro dele (Flint, Lee, Coventry, 1851, p.632).

Buscando razões fisiológicas para o fenômeno e desconsiderando a suposição de comunicação espiritual até que fossem refutadas todas as causas físicas, os médicos deduziram a hipótese dos músculos estalantes com base no aparente cansaço da irmã mais nova, Kate Fox, após a sessão. Eles consideraram que o cansaço seria decorrente do grande esforço físico realizado para produzir os ruídos. De acordo com esses médicos, a confirmação da hipótese apoiou-se em uma mulher capaz de fazer sons semelhantes com movimentos de rotação da tíbia e do fêmur, geradores de estalos (Flint, Lee, Coventry, 1851, p.633).

A explicação teve por consequência o convite das irmãs Fox para testarem sua hipótese em uma de suas sessões. Após sucessivas experiências, que consistiam na imobilização das pernas de Maggie e no apoio das mãos dos médicos para sentir o fêmur e a tíbia da médium, eles não conseguiram demonstrar sua hipótese; contudo, os autores se valeram de outros depoimentos para afirmar que os estalos poderiam ser realizados em outras partes do corpo (Flint, Lee, Coventry, 1851, p.635-636). Explicação semelhante foi dada na Europa e publicada nos anais da Academia de Ciências da França.

Em 1859, o médico-cirurgião Alfred Velpeau publicou uma nota sobre a descoberta do médico alemão Moritz Schiff, professor de anatomia comparada em Berna, expondo que os 
ossos humanos poderiam produzir grandes barulhos, como estalos, a partir do movimento de rotação da coxa, imitando as batidas dos supostos espíritos (Lamballe, 18 abr. 1859, p.760).

Observando casos semelhantes, o médico-cirurgião Armand Jobert Lamballe, membro da Academia de Ciências francesa, afirmou que regiões do corpo como o quadril, o ombro e a parte interna do pé também poderiam produzir barulhos perceptíveis até mesmo em outra sala. Ele afirmou que esse movimento poderia ser realizado inconscientemente, por meio do natural relaxamento das fibras musculares (Lamballe, 18 abr. 1859, p.763).

Alguns historiadores consideram que a exposição a fraudes de médiuns mercenários foi a maior causa para o declínio do espiritualismo (Lamont, 2004).

\section{Causas físicas}

Em maio de 1853, nos primeiros meses em que as mesas girantes ocuparam os noticiários europeus, a Academia de Ciências da França organizou uma comissão investigativa destinada a examinar a natureza dos fenômenos. Ela era composta pelo químico Michel Chevreul e pelos físicos Jacques Babinet e François Arago.

Para os membros da comissão, a rotação das mesas seria resultado da ação inconsciente das pessoas postas ao redor delas (Arago, Barral, Flourens, 1854, p.457-459). As mãos posicionadas sobre a mesa estariam sujeitas a acumulação e dispersão de pequenos impulsos musculares, pouco perceptíveis para o sentido humano, mas rápidos e fortes o suficiente para provocar o deslocamento de grandes massas (Chevreul, 1854, p.170-171; Babinet, 1856, p.241-242).

No mesmo ano, Michael Faraday publicou uma explicação semelhante. O físico inglês investigou médiuns em quem confiava, realizando uma experiência cujo objetivo era verificar a possibilidade de os participantes da sessão pressionarem a mesa sem perceber. Para isso, prendeu pastilhas de cera e terebintina sobre um cartão fixado na borda da mesa. Após a sessão, Faraday (1853, p.190) observou que os cartões estavam marcados com os dedos dos participantes, simulando movimento na mesma direção da rotação da mesa. Ele concluiu que a expectativa dos médiuns em produzir o fenômeno psíquico fazia com que eles aplicassem, inconscientemente, uma força na ponta dos dedos em favor do lugar para onde a mesa girava.

Alguns pesquisadores reconheciam que seus estudos apenas apontavam um caminho de investigação para a explicação dos fenômenos a partir da fisiologia humana, sendo necessários mais estudos sobre essas complexas manifestações (Faraday, 1853; Chevreul, 1854). Embora considerassem suficientes suas teorias para explicar os ruídos e movimentos das mesas, elas contemplavam somente uma pequena parte do conjunto de fenômenos relatados, excluindo de seu campo aqueles considerados inteligentes, como a resposta a perguntas por meio de batidas e a escrita sobre uma cesta. Babinet limitou-se a afirmar a impossibilidade desse tipo de manifestação inteligente pelas leis físicas conhecidas (Babinet, 1856, p.39-41). Por sua vez, Faraday (1853, p.190) reconhecia que sua explicação era insuficiente para dar conta de todas as formas de manifestações mediúnicas existentes. Confiante na explicação física, sugeriu que mais investigações fossem realizadas por outros pesquisadores.

Ao considerar as mesas girantes consequência da pressão involuntária das mãos dos médiuns, os pesquisadores abriram campo para a investigação das causas psicológicas dos atos inconscientes. A ilusão/alucinação tornou-se uma das principais explicações para as manifestações. 


\section{Ilusão e alucinação}

Os pesquisadores dessa hipótese concordavam com a ideia de que a imaginação gerada pelo desejo dos participantes de que o fenômeno fosse real seria a causa da ilusão em espíritos. Eles estudaram os fatores psicológicos que poderiam levar a ilusão ou alucinação dos participantes das sessões.

O médico escocês James Braid (1853, p.3-4) criou uma das primeiras formulações do conceito psicológico de "ideia fixa" para explicar o fenômeno das mesas girantes. Ele explicou que a rotação das mesas seria o resultado da ação muscular sem esforço consciente produzida por uma ideia dominante.

William Benjamin Carpenter (1853, p.5), médico britânico, chamou a crença nas mesas girantes de uma epidemia de delírio que poderia ser atribuída "ao desejo emocional de algum tipo de certeza da continuidade da existência dos amigos falecidos e, portanto, da nossa própria existência futura". Para ele, a mente dos médiuns estaria subjugada a uma ideia dominante por meio da sugestão (p.509). Desse modo, o médium não teria a habilidade de duvidar de uma ideia, agindo como autômato (p.547). Adepto das explicações de Faraday, o autor interpretou o fenômeno das mesas girantes da seguinte forma:

Um número de indivíduos senta-se em volta de uma mesa, em que o movimento, quer para a direita ou para a esquerda, é geralmente combinado no início da experiência ... Como em tantos outros casos, a contínua concentração da atenção sobre uma certa ideia lhe dá um poder dominante, não só sobre a mente, mas ao longo do corpo, e os músculos tornam-se os instrumentos involuntários pelos quais são levados à operação (Carpenter, 1853, p.547-549).

Nos anos seguintes, Carpenter elaborou o conceito de "ação involuntária produzida por uma ideia dominante", com a noção de "cerebração inconsciente", que se tornou uma das principais explicações para as ações produzidas por um ser não desperto. Ele também foi o criador do nome "efeito ideomotor", hoje utilizado pela psicologia para designar movimentos musculares inconscientes (Crabtree, 1993, p.256).

Uma publicação anônima de 1855 expôs uma teoria complementar à ilusão e à alucinação do médium. De acordo com o documento, manifestações psíquicas, como a escrita mediúnica, poderiam ser explicadas por intermédio de uma predisposição do médium ao "desdobramento de personalidade". Nessa condição,

mesmo na mais enérgica concentração, nós não constituímos nossos pensamentos, nós não fazemos mais do que criar e acelerar a aparição deles. Eles nascem nas profundezas misteriosas de nossas mentes, e é só quando eles ganham vida que eles se mostram a nós no teatro da consciência. $\mathrm{E}$ tem mais: as ideias que se apresentam assim presumem uma série de outras que nunca se deixam ver, como em um espetáculo... nós não temos diante de nós mais do que os atores, e não notamos jamais autores ou qualquer um dos muitos agentes cujo envolvimento é essencial para o desempenho da peça (Second Lettre..., 1855, p.10).

A teoria da segunda personalidade não teve grande repercussão na época. Quase trinta anos mais tarde, o psiquiatra Pierre Janet (1903, p.377-401) retomou essa teoria e a considerou uma das primeiras especulações da sua tese sobre a desagregação de personalidade. 
Essas explicações satisfizeram alguns investigadores, enquanto outros afirmavam que o fenômeno, em toda sua abrangência, ainda continuava inexplicado. Para o conde protestante e deputado francês Agénor de Gasparin, as mesas girantes eram cercadas de explicações realizadas a partir de testemunhos e observações insuficientes do fenômeno. Em crítica à hipótese dos movimentos musculares inconscientes para explicar as mesas girantes, Gasparin (1857, p.93) afirmou que

a mesa não se limita a girar. Ela levanta seus pés, atinge números indicados pelo nosso pensamento, em uma palavra, ela obedece à vontade, e obedece tão bem que a supressão do contato não suprime a sua obediência. Impulsão lateral ou atração, que representam as rotações, não podem explicar as elevações!

Gasparin e outros pesquisadores cogitavam a existência de uma força imponderável que seria o agente responsável pelo movimento dos objetos. Essa força estaria presente na natureza e seria pouco conhecida pela ciência até então.

\section{Forças fluídicas}

A ação de forças físicas imponderáveis foi uma das teorias mais exploradas para a explicação das mesas girantes. A voga do magnetismo animal e os estudos científicos da eletricidade tornavam provável a tese da atuação das forças invisíveis sobre a matéria. Acreditava-se que forças poderiam ser retidas e emanadas pelo corpo humano, atuando sob a forma de fluido, definido na época como: "Substâncias hipotéticas criadas pelos físicos para compreender os fenômenos naturais que eles não podem relacionar com outras substâncias conhecidas" (Lachâtre, 1869, p.199).

$\mathrm{Na}$ mesma época em que as teses do magnetismo animal começaram a repercutir na sociedade francesa, o médico Luigi Galvani publicou seus primeiros resultados sobre a relação entre o fluido elétrico e o corpo dos animais, o que chamou de "eletricidade animal" (Bresadola, 1998).

Em 1846, a teoria de Galvani foi analisada pela comissão da Academia de Ciências da França na investigação dos movimentos de atração e repulsão de objetos de uma mesa sem o uso de força aparente atribuídos a Angélique Cottin, apelidada "garota elétrica" (Arago, Barral, Flourens, 1854, p.453-456). Na Inglaterra, John Prichard (1853, p.15-16), membro da Royal College of Surgeons, acreditava que as mesas giravam pela ação de um agente elétrico que permeava os espaços da matéria. Os dedos dos médiuns seriam terminais elétricos capazes de preencher tais espaços, causando o movimento contrário à gravidade.

No entanto, parte dos adeptos dessa teoria considerava que as propriedades já bem conhecidas da eletricidade e do magnetismo terrestre não seriam adequadas à análise do fenômeno (Samson, 1852; Gentil, 1853). Eles defendiam a existência de um fluido presente na natureza e ainda não identificado pela ciência. O "novo fluido" serviria de intermediário entre a alma e a matéria, sendo o elemento responsável pelas manifestações psíquicas (Samson, 1852, p.13-17; Roubaud, 1853, p.30).

Os adeptos dessa hipótese defendiam que essa substância seria a responsável por provocar barulhos e mover objetos a distância. O fluido ainda poderia ocasionar a superexcitação do cérebro do médium, que em alguns casos demonstrava maior percepção mental, permitindo 
o conhecimento de eventos distantes e de pensamentos de seus assistentes (Samson, 1852, p.25; Townshend, 1854).

Os fluidistas rejeitavam a hipótese da manifestação de espíritos desencarnados levantada pelos espiritualistas. Em sua teoria, alegavam que as comunicações mediúnicas decorriam do organismo humano e que o médium transmitia ecos do pensamento (Gentil, 1853, p.284286). O processo era executado de forma inconsciente, tanto por parte do médium quanto dos participantes (Rogers, 1853, p.135).

Diversas especulações sobre a possibilidade de o pensamento consciente atuar em paralelo com a atividade mental inconsciente foram feitas pelos fluidistas. Eles sustentavam que o cérebro humano possuiria centros autônomos responsáveis pelas atividades conscientes e inconscientes que poderiam atuar ao mesmo tempo (Rogers, 1853, p.167; Dods, 1854, p.7475). Durante a sessão, os centros de consciência desperta ficariam dormentes, anulando a vontade e a razão, enquanto os centros inconscientes, por meio da ação do fluido, dariam expressão às ideias do próprio médium ou de seus assistentes, por meio da escrita e das falas mediúnicas ou por ação do fluido em movimentos de objetos e batidas (Rogers, 1853, p.125; Dods, 1854).

O indivíduo também ficaria sujeito à suspensão de sua personalidade no estado de transe, podendo então assumir outras identidades, inclusive a de um suposto espírito desencarnado (Rogers, 1853, p.182).

Partidário dessa hipótese, o filósofo norte-americano George Samson, presidente do Columbian College, hoje George Washington University, afirmava que as informações transmitidas em uma comunicação atribuída aos espíritos eram de conhecimento de algum dos presentes, ainda que inconscientemente (Samson, 1852, p.41-42). Samson ilustrou sua teoria com o caso de uma servente inglesa que, após uma doença que teria afetado seu cérebro, passou a ler a bíblia em hebraico. Descobriu-se que, em sua infância, ela fora criada por uma família judia na qual costumava ouvir a leitura da bíblia em hebraico e também repetir as palavras. De acordo com Samson, esse caso se adequaria à comunicação mediúnica. No momento de superexcitação cerebral, as palavras ouvidas e repetidas em sua infância teriam emergido inconscientemente, sendo falsamente atribuídas a espíritos (Samson, 1852, p.4344). Em 1900, a teoria de Samson foi chamada de criptomnésia pelo psiquiatra Theodore Flournoy (1900).

Assim, o movimento inteligente da mesa seria resultante da ação de fluido ou força emanada do sistema nervoso do médium. Ela seria dirigida pela atividade mental concorrente desconhecida do pensamento consciente; trata-se de uma das primeiras especulações sobre a possibilidade de uma atividade mental inconsciente (Crabtree, 1993, p.253).

\section{Ação espiritual}

Esse grupo atribui o movimento das mesas e as mensagens mediúnicas à ação de personalidades inteligentes invisíveis. Seus adeptos defendiam que esses fenômenos forneciam evidências de que uma fonte inteligente, além dos participantes das sessões, seria a causa dos mesmos. Partiam do princípio de que o grande número de mensagens supostamente escritas por personalidades incorpóreas tenderia a justificar a hipótese da intervenção dos espíritos. Segundo o jornalista norte-americano Herman Snow (1853, p.46-47), tais fenômenos 
talvez pudessem ser atribuídos à eletricidade, ao magnetismo, ao mesmerismo, ou a algum outro poder, não igualmente misterioso em relação à afirmação da ação de espíritos invisíveis - se não fosse uma dificuldade intransponível. Faço alusão ao fato inquestionável de que os fenômenos singulares em questão não são impulsivos e cegos em sua ação: pelo contrário, eles transmitem, da forma mais clara e decisiva, as manifestações da mente. O telégrafo elétrico, com todo o seu poder maravilhoso, não pode transmitir uma linha sequer de pensamento conectado sem uma mente inteligente para guiá-lo. Agora, de onde vêm essas mensagens? Esta é outra e decisiva questão. Se for satisfatoriamente provado que elas não vêm das mentes daqueles que estão visivelmente presentes, então elas devem provir de mentes em uma forma invisível.

Os espiritualistas concordavam que a causa dos fenômenos eram os espíritos; no entanto, possuíam diferentes opiniões sobre a natureza deles. Espiritualistas como o reverendo norteamericano C.H. Harvey (1853, p.107) afirmavam que as comunicações obtidas por intermédio das mesas e de outros meios eram de "espíritos glorificados" que possuíam grande ciência e sabedoria. Alegavam que esses fenômenos poderiam ser comparados com igual validade aos relatos sobrenaturais presentes na Bíblia.

Outra hipótese era de que as comunicações eram realizadas por espíritos demoníacos. Jules Eudes, o marquês de Mirville, acreditava que a manifestação da mesa era genuína e que só poderia ser explicada pela atuação de agentes inteligentes invisíveis. Mirville (1863) insistia, todavia, que os agentes que moviam as mesas e se comunicavam eram espíritos malignos que também estavam associados à clarividência e à leitura da mente.

Contudo, nem todos os representantes da Igreja católica consideravam os fenômenos mediúnicos perigosos. O abade Almignana (1854), que chegou a considerar a possibilidade de o demônio estar atuando sobre as mesas girantes, rejeitou essa hipótese quando não identificou sinais de possessão entre os participantes. Ao questionar os médiuns durante as sessões sobre variados temas, Almignana observou que o conhecimento que eles possuíam não poderia advir deles próprios nem de seus assistentes. Concluiu que as comunicações eram dadas pelos mortos.

A hipótese poliespírita considerava a possibilidade de os fenômenos serem produzidos por inteligências extracorpóreas (espíritos) que viveram na terra, possuindo diferentes graus de bondade, de malícia, de saber e de ignorância.

Um dos mais influentes defensores dessa hipótese foi o intelectual francês Allan Kardec. Embora considerasse válidas as hipóteses de charlatanismo, ilusão, causas físicas e forças fluídicas, afirmava que elas só seriam capazes de explicar os fenômenos parcialmente (Kardec, 1869, p.36-46; Moreira-Almeida, 2008). Para ele, a teoria espírita seria a mais abrangente e adequada para explicar manifestações indicativas da persistência da existência e atividade de uma mente ligada a uma pessoa falecida. Esses fenômenos se referiam especialmente a conhecimentos, habilidades e traços de personalidade compatíveis com pessoas falecidas específicas, mas não possuídos pelos médiuns, tais como: médiuns analfabetos escrevendo (Kardec, 1861, p.193-198); pintar e desenhar habilmente sem nenhum treinamento prévio e sem exibir essas habilidades em suas vidas comuns (Kardec, 1858); escrever poemas sem conhecimento prévio das regras de poesia e sem experiência prévia com esse tipo de arte (Kardec, 1857, p.20); falar ou escrever corretamente em línguas que não conheciam (Kardec, 1860, p.77-81); escrever com letra semelhante à da alegada personalidade comunicante 
quando viva sem ter visto previamente a caligrafia do falecido (Kardec, 1857, p.20); demonstrar características como caráter, humor e escolha de palavras relacionadas com o espírito comunicante que eram desconhecidas dos médiuns (Kardec, 1858, p.19-20, 1859).

Assim como a hipótese de intervenção espiritual apresentada pelos espiritualistas, as demais hipóteses para os fenômenos psíquicos, nesse momento, eram especulações em busca de reconhecimento da comunidade científica e da sociedade da época.

\section{Considerações finais}

Neste artigo, objetivou-se apresentar uma breve revisão de alguns dos mais influentes pesquisadores dos fenômenos psíquicos na primeira metade do século XIX, enfatizando as principais hipóteses para essas manifestações. Por várias décadas no século XIX, os fenômenos psíquicos foram tema de intensa investigação e debates, gerando um grande número de publicações. Essas discussões envolveram diretamente a classe médica e representantes da nascente psicologia. Os fenômenos psíquicos forneceram um amplo leque de experiências que se tornaram objeto de investigação das nascentes ciências da mente. Foram levantadas e debatidas diversas hipóteses explicativas que, embora não se tenha chegado a consenso ou paradigma aceito pela maioria dos investigadores, tais discussões trouxeram implicações para a compreensão da mente e seus transtornos, notadamente na área do inconsciente e da dissociação. Embora pouco conhecidas na atualidade, essas investigações constituem parte importante da história da psicologia e da psiquiatria.

Reconhece-se que o panorama apresentado representa um recorte temporal e geográfico limitado do debate ocorrido; no entanto, abrange os principais desenvolvimentos do início desses debates e investigações ocorridos na Europa ocidental e nos EUA. Dessa parte da história da ciência da mente necessita ser mais bem conhecida e investigada. Dentre aspectos que merecem posteriores investigações, destacamos a expansão dos estudos para outras regiões e culturas não incluídas neste texto, bem como para as décadas seguintes com o intuito de compreender melhor a investigação acadêmica dos fenômenos psíquicos, com apogeu no final do século XIX e seu virtual desaparecimento ao longo da primeira metade do século XX.

\section{AGRADECIMENTO}

Agradecemos à Fundação de Amparo à Pesquisa do Estado de Minas Gerais (Fapemig) pelo financiamento da pesquisa (processo CDS-APQ-01691-10) que resultou na produção deste artigo.

\section{NOTAS}

${ }^{1}$ Palavra utilizada pelos adeptos da hipótese de que as manifestações psíquicas seriam decorrentes da ação exclusiva do fluido magnético ou mesmérico no corpo do indivíduo (Crabtree, 1993).

${ }^{2}$ Refere-se a fenômenos originados da mediunidade, que pode ser definida como uma experiência na qual o indivíduo (médium) alega estar em comunicação com, ou sob o controle de, uma personalidade já falecida ou algum tipo de ser imaterial (Moreira-Almeida et al., 2008).

${ }^{3}$ Palavra utilizada pelos defensores da hipótese de que as manifestações psíquicas seriam resultantes da interação entre espírito e matéria (Kardec, 1868, p.3-4; Britten, 1883).

${ }^{4}$ Definidas pelo fisiologista Charles Richet (1922), manifestações metapsíquicas são caracterizadas pela atuação de forças inteligentes desconhecidas que determinam os pressentimentos, as telepatias, os movimentos sem 
contato de objetos, as aparições e certos fenômenos mecânicos e luminosos, compreendendo-se nelas os notáveis fenômenos intelectuais das nossas inconsciências.

5 O termo "parapsíquico" foi cunhado pelo filósofo francês Émile Boirac (1851-1917) para definir todo fenômeno produzido por seres vivos ou como resultado da ação deles. Tais fenômenos não podem ser inteiramente explicados por leis e forças naturais conhecidas e que possuem relações com a consciência e com a mente (Fodor, 1934, p.577).

\section{REFERÊNCIAS}

ALMEIDA, Angélica.

Uma fábrica de loucos: psiquiatria $\mathrm{x}$ espiritismo no Brasil (1900-1950). Tese (Doutorado em História) - Universidade Estadual de Campinas, Campinas. 2007.

ALMIGNANA, Abade.

Du somnambulisme, des tables tournantes et des médiums, considérés leurs rapports avec la théologie et la physique. Paris: Dentu et Germer-Baillière. 1854.

ALVARADO, Carlos.

Fenômenos psíquicos e o problema mente-corpo: notas históricas sobre uma tradição conceitual negligenciada. Revista de Psiquiatria Clínica, v.40, n.4, p.157-161. 2013.

ARAGO, François; BARRAL, Jean; FLOURENS, Pierre.

Oeuvres completes de François Arago. v.4. Paris: Gide et J. Baudry. 1854.

AUBRÉE, Marion; LAPLANTINE, François. La table, le livre et les esprits. Paris: Édition JeanClaude Làttes. 1990.

BABINET, Jacques.

Études et lectures sur les sciences d'observation et leurs applications pratiques. Paris: Mallet-Bachelier. 1856.

BARRIER, Jean.

Les spiritualists d'Amérique. L'Univers. Paris: 26 jul. 1852.

BERTRAND, Alexandre.

Du magnétisme animal en France. Paris: J.B. Baillière. 1826.

BILLOT, Guillaume Pascal.

Recherches psychologiques sur la cause des phénomènes extraordinaires observés chez les modernes voyans: improprement dits somnambules magnétiques. Paris: Albanel \& Martin. 1839.

BRAID, James.

Hypnotic therapeutics, illustrated by cases: with an appendix on table-moving and spirit-rapping. Monthly Journal of Medical Science, v.17, p.14-47. 1853.
BRESADOLA, Marco.

Medicine and science in the life of Luigi Galvani (1737-1798). Brain Research Bulletin, v.46, n.5, p.367-380. 1998.

BRITTEN, Emma H.

Nineteenth century miracles: or, spirits and their work in every country of the earth. New York: William Britten/Lovell \& Company. 1883.

BURDIN, Charles; DUBOIS, Frédéric.

Histoire académique du magnétisme animal. Paris: J.B. Ballière. 1841.

\section{CAHAGNET, Louis A.}

The celestial telegraph: or, The secrets of the life to come revealed through magnetism. London: Geo. Peirce, 310, Strand. 1850.

CARPENTER, William.

Electrobiology and mesmerism. Quarterly Review, v.93, p.501-557. 1853.

\section{CHARDEL, Casimir M.}

Esquisse de la nature humaine expliquée par le magnétisme animal. Paris: Encyclopédie Portative. 1826.

CHEVREUL, Michel.

De la baguette divinatoire, du pendule dit explorateur et des Tables tournantes, au point de vue de l histoire, de la critique et de la méthode experimentale. Paris: Mallet-Bachelier. 1854.

CRABTREE, Adam. From Mesmer to Freud: magnetic sleep and the roots of psychological healing. New Heaven; London: Yale University. 1993.

CUCHET, Guillaume.

Les voix d'outre-tombe: tables tournantes, spiritisme et société au XIX ${ }^{\mathrm{e}}$ siècle. Paris: Le Seuil. 2012.

CUVILLERS, Henin de.

Le magnétisme animal retrouvé dans l'antiquité. Paris: Chez Barrois l'aine. 1821.

DELAAGE, Henri.

Le monde occulte on mystères du magnétisme dévoilés par le somnambulisme. Paris: Paul Lesigne Editeur. 1851.

DELEUZE, Joseph.

Défense du magnétisme animal contre les attaques 
dont il est l'objet dans le Dictionnaire des sciences médicales. Paris: Belin-Leprieur. 1819.

DELEUZE, Joseph; FOISSAC, Pierre. Practical instruction in animal magnetism. Paris: J.B. Baillière; Leipzig: T.O. Weigel. 1850.

DELEUZE, Joseph; ROSTAN, Léon L. Instruction pratique sur le magnétisme animal, augmentée d'un chapitre du docteur L. Rostan. Paris: Société Pour Les Publications Littéraires. 1836.

DODS, John.

Spirit manifestations examined and explained: Judge Edmonds refuted; or, an exposition of the involuntary powers and instincts of the human mind. New York: De Witt \& Davenport. 1854.

DOYLE, Arthur Conan.

História do espiritismo. São Paulo: Pensamento. 2007.

DUBOIS, Frédéric.

Examen historique et résumé des expériences prétendues magnétiques faites par la commission de l'Académie Royale de médecine. Paris: [s.n.]. 1833.

\section{ELLENBERGER, Henri.}

The discovery of the unconscious: the history and evolution of dynamic psychiatry. New York: Basic Books. 1970.

FARADAY, Michael.

Professor Faraday on table-moving. Athenaeum, n.1340, p.801-803. 1853.

FLINT, Austin; LEE, Charles; COVENTRY, Charles Brodhead.

Discovery of the source of the Rochester Knockings. Buffalo Medical Journal, v.6, p.628633. 1851.

FLOURNOY, Théodore.

Des Indes à la planète Mars; étude sur un cas de somnambulisme avec glossolalie. Paris: Alcan. 1900.

FODOR, Nandor.

Encyclopedia of psychic science. London: Arthurs Press. 1934.

FOISSAC, Pierre.

Mémoire sur le magnétisme animal, adresse à MM. les membres de l'Académie des sciences et de l'Académie royale de médecine. Paris: Didot le Jeune. 1825.

GASPARIN, Agénor.

Science vs. modern spiritualism: a treatise on turning tables, the supernatural in general, and spirits, v.1. New York: Kiggins \& Kellogg. 1857.

GAULD, Alan.

The founders of psychical research. London: Routledge \& Kegan Paul Ltd. 1968.
GENTIL, Joseph.

Magnétisme-somnambulisme: manuel élémentaire de l'aspirant magnétiseur. Paris: E. Dentu. 1853.

GIUMBELLI, Emerson.

O cuidado dos mortos: uma história da condenação e legitimação do espiritismo. Rio de Janeiro: Arquivo Nacional. 1997.

GONÇALVES, Valéria P.; ORTEGA, Francisco. Uma nosologia para os fenômenos sobrenaturais e a construção do cérebro "possuído" no século XIX. História, Ciências, Saúde-Manguinhos, v.20, n.2, p.373-389. abr.jun. 2013.

HASTINGS, Arthur.

With the tongues of men and angels: a study of channeling. Fort Worth, Texas: Holt, Rinehart and Winston. 1991.

HARVEY, Cassias H.

Millenial dawn, or spiritual manifestations tested.

Carbondale: S.S. Benedict. 1853.

JABERT, Alexander.

Estratégias populares de identificação e tratamento da loucura na primeira metade do século XX: uma análise dos prontuários médicos do Sanatório Espírita de Uberaba. História, Ciências, Saúde-Manguinhos, v.18, n.1, p.105-120. jan.-mar. 2011.

JAMES, Frank A.J.L.

Michael Faraday: a very short introduction.

Oxford: Oxford University Press. 2010.

JANET, Pierre.

L'Automatisme psychologique. Paris: Félix Alcan. 1903.

JUNG-STILLING, Johan H.

Theory of pneumatology: in reply to the question, what ought to be believed. New York: J.S. Redfield. 1854.

KARDEC, Allan.

Le livre des mediuns. Paris: E. Dentu. 1869.

KARDEC, Allan.

La genèse: les miracles et les prédictions selon le spiritisme. Paris: Typ. de Rouge frères, Dunon et Fresné. 1868.

KARDEC, Allan.

Revue spirite: journal d'études psychologiques. v.4. Paris: Impr. de Rouge frères, Dunon et Fresné. 1861.

KARDEC, Allan. Revue spirite: journal d'études psychologiques. v.3. Paris: Impr. de Rouge frères, Dunon et Fresné. 1860. 
KARDEC, Allan.

Revue spirite: journal d'études psychologiques. v.2. Paris: Impr. de Rouge frères, Dunon et Fresné. 1859.

KARDEC, Allan.

Revue spirite: journal d'études psychologiques. v.1. Paris: Impr. de Rouge frères, Dunon et Fresné. 1858.

KARDEC, Allan.

Le livre des esprits. Paris: E. Dentu. 1857.

KERNER, Justinus A.

The Seeress of Prevorst: being revelations concerning the inner-life of man and the interdiffusion of a world of spirits in the one we inhabit. London: Partridge \& Brittan. 1855.

LACHÂTRE, Maurice.

Nouveau dictionnaire universel. Paris: F. Cantel. 1869.

LAMBALLE, Jobert.

De la contraction rythmique musculaire involontaire. Annales de l'Académie des sciences. p.760-763. 18 abr. 1859.

LAMONT, Peter.

Spiritualism and a mid-victorian crisis of evidence. The Historical Journal, v.47, n.4, p.897920. 2004.

LE MALÉFAN, Pascal; EVRARD, Renaud; ALVARADO, Carlos S.

Spiritist delusions and spiritism in the nosography of French psychiatry (1850-1950). History of Psychiatry, v.24, n.4, p.477-491. 2013.

MÉHEUST, Bertrand.

Somnambulisme et médiumnité, t.2: le choc des sciences psychiques. Paris: Synthélabo. 1999.

MESMER, Franz A.

Mémoire sur la découverte du magnétisme animal. Paris: P. Fr. Didot le jeune. 1779.

MIRVILLE, Jules E.

Pneumatologie: manifestations fluidiques devant la science moderne. Paris: H. Vrayet de Surcy. 1863.

MONROE, John.

Laboratories of faith: mesmerism, spiritism, and occultism in modern France. Ithaca: Cornell University Press. 2008.

MOREIRA-ALMEIDA, Alexander.

Allan Kardec and the development of a research program in psychic experiences. Proceedings of Presented Papers, v.51, p.136-151. 2008.

MOREIRA-ALMEIDA, Alexander et al. Versão em português da escala de religiosidade da Duke - Durel. Revista de Psiquiatria Clínica, v.35, p.31-32. 2008.
OPPENHEIM, Janet.

The other world: spiritualism and psychical research in England, 1850-1914. Cambridge: Cambridge University Press. 1985.

PAGE, Charles G.

Psychomancy: spirit-rappings and table-tippings exposed. New York: D. Appleton. 1853.

PRICHARD, John.

A few sober words of table-talk about table-spirits. London: G.C. Liebenrood. 1853.

PUYSÉGUR, Marquês de.

Recherches, expériences et observations

physiologiques sur l'homme dans l'état du

somnambulisme naturel, et dans le somnambulisme provoqué par l'acte magnétique. Paris : J.G. Dentu. 1811.

PUYSÉGUR, Marquês de.

Du magnétisme animal, considéré dans ses rapports avec diverses branches de la Physique générale. Paris: Imprimerie de Cellot. 1809.

RICHET, Charles.

Traité de metapsychique. Paris: Librairie Félix Alcan. 1922.

ROGERS, Edward C.

Philosophy of mysterious agents, human and mundane. Boston: J.P. Jewett. 1853.

ROUBAUD, Félix.

La danse des tables: phénoménes physologiques démontrés. Paris: Librairie Nouvelle. 1853.

ROSTAN, Léon L.

Du magnétisme animal. Paris: Rignoux. 1825.

SAMSON, George W.

"To daimonion". Massachusetts: Gould and Lincoln. 1852.

SECOND LETTRE...

Seconde lettre de gros Jean à son évêque au sujet des tables parlantes, des possessions et autre diableries. Paris: Ledoyen. 1855.

SHARP, Lynn.

Secular spirituality: reincarnation and spiritism in nineteenth-century France. Lanham: Lexington Books. 2006.

SNOW, Herman.

Spirit-intercourse: containing incidents of personal experience while investigating the new phenomena of spirit thought and action: with various spirit communications through himself as medium. Boston: Crosby, Nichols. 1853.

SOCIETY...

Society For Psychical Research (Great Britain). Proceedings of the Society for Psychical Research, v.1. Cambridge, Massachusetts: Harvard University. 1882. 
STROMBECK, Friedrich K.

Histoire de la guérison d'une jeune personne, par le magnétisme animal, produit par la nature elle-même. Paris: Librairie Grecque, Latine, Allemande. 1814.

TESTE, Alphonse.

Manuel pratique du magnétisme animal. Paris: Librairie de J.B. Baillière. 1840.

TOWNSHEND, Chauncy H.

Mesmerism proved true: and the Quarterly Reviewer reviewed. London: T. Bosworth. 1854.

VALENTINE, Elizabeth R.

Guest editorial. History of the Human Sciences, v.25, n.2, p.1. 2012.
VIREY, Julien-Joseph.

Examen impartial de la médecine magnétique, de sa doctrine, de ses procedés, et de ses cures. Dictionnaire des sciences médicales, v.29, p.463558. 1818.

WEISBERG, Barbara.

Talking to the dead: Katie and Maggie Fox and the rise of spiritualism. New York: Harper Collins. 2004. 